\title{
POR QUE JUÍZES APLICAM PADRÕES JURÍDICOS ESPÚRIOS? UMA ABORDAGEM COMPORTAMENTAL
}

\section{WHY JUDGES APPLY SPURIOUS LEGAL STANDARS? A BEHAVIOURAL APPROCH}

\author{
${ }^{1}$ Vinicius De Souza Faggion
}

\section{RESUMO}

É possível que existam regras jurídicas que são simplesmente ruins ou espúrias. Boa parte delas foi criada com o melhor dos propósitos, mas, infelizmente, circunstâncias não previstas ou mudanças de comportamento social tornam sua aplicação injusta ou excessivamente onerosa aos sujeitos atingidos. Curiosamente, regras capazes de produzir soluções ruins ou indesejáveis do ponto de vista moral costumam prevalecer, mesmo em ocasiões nas quais há juízes que optam por desconsiderá-las, fornecendo boas razões para não aplicá-las, em favor de outra decisão. Por que tais padrões jurídicos ainda prevalecem como soluções de disputas reguladas pelo direito? Defendo que a causa dessa persistência é explicada por dois fenômenos estudados no campo da psicologia social, nomeadamente, o experimento da conformidade e submissão à consensos majoritários de Asch e a ignorância pluralista. Caso esteja correto, esses fenômenos ou vieses comportamentais são um obstáculo que impede o prevalecimento de soluções morais mais sensatas sobre alguns casos concretos, pois reforçam uma lógica de aplicação formal do direito.

Palavras-chave: Padrões jurídicos espúrios, Decisão judicial, Conformidade, Submissão, Obediência, Ignorância pluralista.

\begin{abstract}
There may be legal rules that are simply bad or spurious. Much of it was created with the best of intentions, but unfortunately, unforeseen circumstances or social behavioral changes make its application unfair or excessively burdensome to the individuals affected. Interestingly, rules capable of producing bad or undesirable solutions from a moral point of view often prevail even in times when there are judges who choose to disregard them, providing good reasons not to apply them in favor of another decision. Why such legal standards still prevail as disputes solutions ruled by the law? I argue that the cause of this persistence is explained by two phenomena studied by the realm of the social psychology, namely, Aschs experiment of conformity and submission to the consensus of a majority and the pluralistic ignorance. If I am correct, these phenomena or behavioural biases are an obstacle that prevents the prevalence of more sensible moral solutions on some specific cases, because they reinforce a logic of formal application of the law.
\end{abstract}

Keywords: Spurious legal standards, Judicial decision, Conformity, Submission, Obedience, Pluralistc ignoranc.

\footnotetext{
${ }^{1}$ Mestre em Direito pela Pontifícia Universidade Católica do Rio de Janeiro. Pontifícia Universidade Católica do Rio de Janeiro - PUC, Rio de Janeiro. Brasil. E-mail: vsfaggion@ yahoo.com.br
} 


\section{INTRODUÇÃO}

Considere o seguinte caso apresentado por Scott Shapiro (2001, p. 530):

Um grupo de beatas, os "Missionários da Caridade", procurava em um bairro nova iorquino por construções abandonadas em bom estado para abrigar andarilhos contra o inverno frio da cidade. A missionária líder era Madre Teresa de Calcutá, vencedora do Prêmio Nobel da Paz. Junto dos seus ajudantes conseguiu levantar recursos suficientes para a reforma de uma edícula abandonada, e por em funcionamento seu plano de caridade. Em pouco tempo, o albergue inaugurado, apesar de simples e modestamente equipado, servia refeições aos andarilhos, suas roupas eram lavadas à mão, e os desabrigados passavam a noite no terceiro e quarto andares em catres rústicos, mas confortáveis. Porém a missão de caridade não pôde ser mantida. Isso porque o código normativo de construção predial de Nova Iorque contém regra que impede ocupação de prédios reformados que não tenham elevadores instalados. Como os custos para a instalação dos equipamentos eram altos e incompatíveis com os recursos direcionados somente ao cuidado dos andarilhos, Madre Tereza desistiu da missão altruísta, mesmo por acreditar que a presença do elevador não era estritamente necessária ao funcionamento do albergue.

O ponto com que Shapiro (2001, p. 531) quer chegar com o exemplo é de que sistemas jurídicos são envoltos numa racionalidade de "pensar por regras" ("rule-think"), pela qual sempre se olha para uma regra para determinar se determinada ação é justificável ou não sem se considerar se o resultado é justificado pelas suas consequências, muitos menos se a aplicação da regra produz ações intrinsecamente boas ou não. Por consequência, raciocínios dominados por regras podem produzir resultados muito rígidos ou carentes de boa racionalidade.

No caso particular da missão de caridade, o código de leis prediais impediu que uma boa ação pudesse ser levada adiante, uma ação que, arguendo, seria benéfica não somente aos andarilhos e à comunidade, mas ao próprio Estado que proibiu a atividade. A ação das beatas economizaria hipotética receita de seguridade voltada para a assistência dos desabrigados ${ }^{1}$.

1 Shapiro não dedica linhas para descrever as vantagens da missão de caridade. Porém, é oportuno trabalhar o exemplo com mais minúcias. Construir uma hipótese para as vantagens da ação das beatas é importante para defender a causa contra prováveis objeções dos aplicadores da lei municipal. Uma razão provavelmente invocada a favor da regra seria exigência de elevadores como medida de segurança aos ocupantes do imóvel ou para assegurar a usabilidade do prédio por cadeirantes. Porém, dadas as circunstâncias do caso e os propósitos do albergue, essas razões hipotéticas não soam tão plausíveis. A questão central do caso parece ser sobre a melhoria das condições dos andarilhos. Se comparadas as condições entre viver perambulando pelas ruas, ao invés de ao menos pernoitar num abrigo, a segurança dos andarilhos é maior no segundo cenário. $\mathrm{O}$ mesmo vale para o caso de um desabrigado com dificuldades motoras, ele encontra mais dificuldades em viver desamparado pelas ruas do que auxiliado pelas beatas, mesmo em um abrigo sem elevadores. Desse modo, é possível defender a atividade das beatas, mesmo contra argumentos que protegem a aplicação formal da regra nesse caso. 
Caso Madre Teresa entrasse na justiça para defender a causa da ação de caridade, Shapiro (2001, p. 532) questiona:

Teria sido racional a um juiz desconsiderar os regulamentos?

Não obstante a pressão feroz que o sistema jurídico norte-americano tem recebido nos últimos anos, todos parecem estar bem confortáveis com o raciocínio judicial de regras. De fato, um juiz que assumiu “corrigir" as regulações será bastante criticado pelo ato ultra vires. Mesmo os críticos conservativos mais vociferantes do Estado regulador não advogam que juízes devam ignorar leis devidamente promulgadas ${ }^{2}$.

Esse raciocínio revela dois dados importantes para a abordagem que pretendo propor: primeiro, que existe a possibilidade da existência de regras ${ }^{3}$ cujos propósitos nem sempre soam adequados às circunstâncias concretas de alguns casos. E segundo, mesmo que se reconheça que existam regras cuja aplicação produza mais malefícios que vantagens, há uma postura generalizada tanto dos juízes como de parte da população de que, mesmo a despeito das desvantagens antecipáveis de um raciocínio guiado por regras, os magistrados não devem desprezar a aplicação da regra durante o julgamento.

Com o exemplo dado, almejo assumir que a regulação predial é uma instância de padrão jurídico ruim ou espúrio para o caso concreto. Em sendo espúrio, o padrão poderia ser afastado pelo julgador, desde que a solução alternativa não fosse arbitrária, mas apoiada por razões sensatas que justificassem a decisão contrária à regulamentação. No caso em questão, a solução mais acertada seria considerar lícita a manutenção do albergue pelas beatas, já que traria mais benefícios à comunidade, mesmo em detrimento da aplicação da regra.

O caso apresentado não é único. É possível conceber outras hipóteses nas quais a aplicação de regras jurídicas pela autoridade julgadora é capaz de produzir resultados moralmente inferiores ou injustos, caso comparados a decisões que desconsiderassem as regras por outras razões. Brand-Ballard (2010, p. 78) apresenta alguns casos cuja aplicação da regra não parece trazer os melhores resultados: um tribunal sentencia à prisão por furto um ativista ambiental que invadiu um laboratório que fazia experimentos proibidos em animais, para libertá-los do sofrimento; outro tribunal sentencia o réu por tráfico de entorpecentes ao plantar maconha para fins medicinais de eficiência clinicamente comprovada; um terceiro

\footnotetext{
2 Tradução livre de: "would it have been rational for a judge to disregard the regulations? Despite the ferocious pounding the American legal system has received in the last few years, everyone seems to be very comfortable with judicial rule-think. Indeed, a judge who took it upon herself to correct" the regulations would be roundly

criticized for the ultra vires act. Even the most vociferous conservative critics of the regulatory state do not advocate that judges should ignore duly enacted law."

3 Utilizarei o termo "regra" de um modo amplo para denotar não somente regras presentes num código de leis, mas também outros padrões jurídicos, que aplicados ao caso concreto têm força de regra, como princípios jurídicos, ou entendimentos jurisprudenciais consolidados por um tribunal. Desse modo, sugiro tomar expressões como "regras judídicas" e padrões jurídicos" por sinônimos.
} 
tribunal mantém a deportação de imigrante que, apesar de ilegal, contribuiu de forma exemplar à comunidade que se instalou ${ }^{4}$. Dessa forma, é possível conceber outros casos ${ }^{5}$ nos quais é possível encontrar mais vantagens na permissão de condutas contra legem do que na solução legal disponível.

Já Brennan et. al (2013, p. 176) consideram o problema da existência de normas sociais espúrias ou ruins, caracterizando primeiramente o que são normas: um conjunto de atitudes normativas sustentadas por grupos de pessoas ou uma comunidade. Tais normas podem, por bem, ser alteradas pela argumentação ou retórica, ou seja, através de razões para a mudança. Nesse sentido, se há normas que não parecem vantajosas, que motivos há para insistir em mantêlas?

Os autores estudam normas espúrias de um modo em geral, ou seja, sem diferenciar normas não-formais, das formais. As primeiras existem na sociedade, mas não pertencem ao domínio das segundas, estas pertencentes ao direito positivo (BRENNAN, et. al, 2013, p. 40). Um exemplo de norma não-formal espúria seria a prática da sodomia entre recém-casados em dada cultura. Outro exemplo abordado pelos autores é o costume de famílias em sociedades orientais somente casarem filhas com têm seus pés amarrados para atingir um padrão estético apreciado, o chamado "pé de lótus"6.

A título de exemplo comum, também é possível que normas formais e não-formais coincidam com frequência. Como é o caso da regra contra o homicídio, reconhecida formalmente pelo direito como crime, e reprovada não-formal e moralmente como norma do costume social.

\footnotetext{
${ }^{4}$ Os exemplos dados pelo filósofo podem preocupar certos leitores, por sequer considerarem a hipótese de que tais decisões sejam permissíveis, muito menos considerar as regras jurídicas desprezadas pelos juízes casos de normas inadequadas ou ruins aos casos concretos que regulam. Ballard $(2009$, p. 79$)$ alerta que, para aceitar a pemissibilidade de uma decisão judicial que despreza regras do direito, é necessário avaliar cada caso através de teorias de justiça distributiva, às quais não espera concordância de todas as pessoas. Ainda sim, os exemplos não devem ser excluídos de análise simplesmente por parecerem disparatados. Uma pessoa sensata e aberta à possibilidade de considerar com seriedade a alternativa de desconsiderar a regra num caso concreto, pode chegar à conclusão de que um veredito baseada em regras realmente não soa ser a melhor estratégia de decisão.

${ }^{5}$ Mais casos semelhantes a esses podem também ser encontrados em Moore (2007, p. 1531-1536) e em Hurd (2003, p. 12-21).

${ }^{6}$ A prática do "pé de lótus" seria uma norma social espúria já que as mulheres que ofereceram seu dote ficam com os pés deformados a ponto de sofrerem para caminhar ou impossibilitá-las permanentemente à locomoção.
} 
Tais normas espúrias tendem a persistir, pois se encontram internalizadas na sociedade onde surgiram. Desse modo, a não ser que pessoas considerem a norma como prática espúria e consigam transformar as inclinações da grande maioria das pessoas, tentativas deliberadas de alterá-las ou desprezá-las somente causarão reprovação crítica daqueles que vêm vantagens nas normas ruins. No caso das regras jurídicas, as consequências são ainda maiores, além da reprovação moral, aqueles que tentam desafiar a ineficiência da regra podem ser sancionados legalmente.

Um exemplo real da aplicação normas formais, ou melhor, de padrões jurídicos espúrios se refere ao entendimento sedimentado pelos tribunais superiores de que não cabe alegar o princípio da insignificância para afastar a condenação pelo crime de tráfico de entorpecentes. Tal posicionamento majoritário persiste em ser aplicado e produz vereditos que condenam réus abordados por uma quantidade ínfima de droga ${ }^{7}$. As razões constantemente invocadas são:

\begin{abstract}
Segundo precedentes do STF e do STJ, o delito de tráfico de drogas não comporta a incidência do princípio da insignificância, visto que se cuida de delito de perigo abstrato praticado contra a saúde pública. Dessa forma, para esse específico fim, é irrelevante a pequena quantidade da substância apreendida (no caso, 0,2 decigramas de crack) ${ }^{8}$.
\end{abstract}

Nesse caso, considera-se a aplicação do entendimento majoritário dos tribunais superiores como um padrão jurídico espúrio por condenar o réu por um ilícito muito pesado, enquanto poderia ser reprimido pela infração bem mais branda, como é o porte de drogas para consumo.

Portanto, tendo em vista que o problema da persistência de normas espúrias é objeto recente de estudo, pretendo focar minha abordagem somente sobre a categoria das normas formais ou regras jurídicas. Apreciarei o problema da persistência na aplicação de regras que soam inadequadas me preocupando apenas com a figura do juiz. Dessa forma, a pergunta que formulo é a seguinte: porque a aplicação de regras espúrias por juízes persistem e dificilmente são alteradas?

\footnotetext{
${ }^{7}$ O portal de notícias jurídicas Justificando relata dois casos cujos Tribunais de Justiça de São Paulo e Minas Gerais condenaram com base no entendimento majoritário seus respectivos réus por tráfico de drogas pelo porte de 1 e 0,02 gramas de droga. Disponível em: http://justificando.com/2015/06/22/insignificancia-homem-econdenado-pelo-stj-por-trafico-de-002g-de-maconha/. O julgado comumente invocado para preservar o entendimento é o Habeas Corpus n. 240.258, da relatora Ministra Laurita Vaz, disponível em: http://stj.jusbrasil.com.br/jurisprudencia/23942152/habeas-corpus-hc-240258-sp-2012-0081813-2-stj/inteiroteor-23942153.

${ }^{8}$ HC 155.391-ES, Rel. Min. Maria Thereza de Assis Moura, julgado em 2/9/2010. 6 a Turma
} 
Para responder a pergunta, me dedicarei em analisar causas comportamentais estudadas pela psicologia social. As causas estão relacionadas a fatores de conformidade e submissão a decisões majoritárias. Assim, tento esboçar uma abordagem sobre uma "psicologia do julgamento" e da atuação judicial, uma área que contém uma pequena literatura relacionada (GUTHRIE; RACHLINSKI; WISTRISCH, 2001 e 2005) e cujo campo de pesquisa assume a figura do juiz como sujeita aos mesmos fatores psicológicos que afetam as pessoas em geral, repercutindo sobre seu julgamento.

Noutras palavras, assumindo a mesma perspectiva dos pesquisadores, defendo que conhecimentos adquiridos sobre a cognição humana e o modo com que pessoas decidem também aplicar-se-ão aos juízes (SCHAUER, 2010, p. 2).

Com esse objetivo, abordarei dois fenômenos comportamentais que ilustram o problema: o experimento conduzido por Solomon Asch e com a ignorância pluralista, uma propensão ou viés comportamental manifestado em grupos sociais. Acredito que ambos conseguem explicar algo sobre o comportamento judicial.

Mas antes de trabalhar especificamente com essas causas, e apresentar uma explicação do que cada uma consiste, é necessário: primeiramente qualificar melhor a relação entre os juízes e a observância a padrões jurídicos institucionalizados. E, em segundo lugar, destacar como a concepção convencional dos deveres atribuídos ao ocupante do papel judicial dificulta a hipótese de alteração de regras espúrias.

\section{LEIS RUINS, MAS DEVERES CONSTANTES}

Para abordar satisfatoriamente o problema dos padrões jurídicos espúrios é preciso compreender a influência que regras do direito exercem sobre os agentes oficiais que as observam, como é o caso dos juízes, protagonistas da análise.

Herbert Hart (1994, p. 91) defende que, para um sistema de regras jurídicas existir, é necessário reportar à noção de regras primárias e secundárias. As do primeiro tipo são responsáveis por ditar direitos e deveres básicos da vida social, são regras que fixam o pagamento de impostos, a capacidade para prática de atos jurídicos, as regras para firmar um contrato, o crime e as sanções que acompanham o seu cometimento, dentre muitas outras. As do segundo tipo fazem parte de um conjunto menos evidente, mas não menos importante; são 
regras que atuam como se atores coadjuvantes fossem: identificam, adicionam, modificam ou subtraem as regras primárias, e também regulam sua aplicação a questões concretas.

São regras endereçadas aos oficiais ou funcionários do direito que exercem um papel jurídico específico, a exemplo dos legisladores e juízes.

Hart também considera que um sistema jurídico de regras só se mantém na medida em que seus agentes oficiais manifestem uma noção de obrigação perante as regras do sistema. Uma regra, para ser jurídica também não pode ser mero hábito de conduta habitualmente obedecido, é necessário aos agentes que observam regras jurídicas exercerem certa pressão social para a observância das mesmas. Essa pressão social se manifesta através do ponto de vista interno do direito, que reflete uma atitude prática de aceitação de regras em dada comunidade, ou seja, a forma pela qual pessoas estão motivadas, têm o dever, ou obrigação de agir e avaliar a conduta dos seus pares de acordo com as regras aceitas (SHAPIRO, 2006, p.

2). Para uma ordem jurídica existir, basta ao menos que o ponto de vista interno esteja presente apenas sobre as atitudes dos oficiais do direito ${ }^{9}$. Logo, "as autoridades devem encarar as normas como padrões comuns de comportamento oficial e avaliar criticamente suas próprias infrações e as dos outros, encarando-as como deslizes. " (HART, 1994, p. 128).

Essas características conceituais acerca da existência de ordenamentos jurídicos apontam que juízes aplicam prescrições contidas em regras primárias, pois são motivados pela obrigação gerada através da aceitação das regras secundárias do direito. Ao decidirem uma disputa judicial aplicam a regra como padrão de conduta sobre tal-e-tal caso. Juízes observam tais regras justamente porque há outros juízes que vêm as mesmas regras como padrões obrigatórios. A persistência das regras jurídicas é explicada pelo dever de obrigação dos oficiais sobre o direito. Eles possuem uma atitude crítico-reflexiva, ou seja, caso um juiz deixe de observar a regra aplicável, certamente os demais juízes e oficiais jurídicos criticarão publicamente a atitude, por esta ser impermissível perante o direito posto.

A noção de obrigação dos juízes constitui um obstáculo teórico à empreitada de uma decisão judicial que desconsidere a aplicação de regras jurídicas válidas. O juiz que assim age terá a missão, não somente de fornecer boas razões para desconsiderar a regra, mas também terá que persuadir seus demais pares, e os outros oficiais do direito (como é o caso dos legisladores que editaram a regra), a alterarem seus padrões crítico-reflexivos quanto à inadequabilidade da aplicação de uma regra ruim.

\footnotetext{
9 Apesar de tal condição conceitual mínima, o próprio Hart considera que é muito improvável, apesar de possível, que existam ordenamentos jurídicos em que apenas os oficiais do direito estejam imbuídos com uma noção de dever ou obrigação à observância das regras (HART, 1994, p. 129).
} 


\section{OS DEVERES COMUMENTE ATRIBUÍDOS AO PAPEL JUDICIAL}

Além do obstáculo da persuasão dos demais oficiais jurídicos sobre regras jurídicas espúrias, até mesmo da reprovação crítica daqueles que acreditam ter a obrigação de seguir a regra, há ainda outra dificuldade: o risco de desvio da função judicial. Um juiz que deixa de aplicar a lei ainda está agindo como um juiz, ou seja, ainda está praticando o papel judicial?

Para compreender essa dificuldade é preciso notar que a função de juiz é um papel social, composto por um conjunto de normas, valores e expectativas que recaem sobre um agente pelo fato deste manter aquele papel (GREEN, 2014, p. 10). Por exemplo, considere o papel de uma baby-sitter, sua função essencial é tomar conta de crianças pequenas de terceiros. Uma norma adequada à função desempenhada pode ser "evitar sempre que crianças entrem em apuros"; um valor do papel pode ser algo como "prezar pela vigilância sempre atenta das crianças"; e uma expectativa, a daquele que contrata os serviços da babá, é encontrar seus filhos saudáveis, bem alimentados e na mesma situação que os deixaram ao sair de casa para o trabalho.

E o caso do juiz? Que conjunto de normas, valores e expectativas circunscrevem o papel judicial? O conjunto de normas são as regras secundárias que motivam a noção de dever do juiz, especialmente as regras de adjudicação pertinentes ao exercício do julgamento e ao reconhecimento das regras válidas aplicáveis ao caso concreto. $\mathrm{O}$ valor do papel pode ser algo como prezar pela aplicação correta da regra primária de acordo com o padrão crítico-reflexivo manifesto pelos demais juízes. Já a expectativa é que, no fim do expediente, o juiz aplique a regra convencionada conforme determina o sistema jurídico. 
Essas considerações acerca do exercício do papel judicial permitem explicar a passagem já apresentada no texto de que juízes e pessoas da comunidade em geral, mesmo as críticas ferrenhas que desaprovam um Estado excessivamente regulador, não aprovam a atitude de um juiz desconsiderar leis corretamente promulgadas. Os sujeitos assim o fazem justamente por acreditarem num dado conjunto de funções e deveres inerentes ao papel judicial. A essa impressão generalizada que a sociedade tem a respeito do papel judicial criam-se as seguintes considerações entre os juízes e as regras que devem aplicar:

Tem sido sugerido que as leis são generalizações que predizem as decisões dos juízes, que as leis são normas endereçadas aos juízes, que as leis são normas que os juízes estão designados a aplicar, e que as leis são normas àqueles que estão sujeitos a decisões judiciais são obrigados a obedecer. (GREEN, 2014, p. 01) ${ }^{10}$

Avançar com essa impressão acima implica se comprometer com uma visão bem estreita do papel judicial $^{11}$, nomeadamente, aquela que sustenta que qualquer padrão do qual o juiz tem obrigação de empregar em decisões faz sempre parte do direito institucionalizado, ou que o papel judicial é conformado apenas com constelações de deveres institucionalmente organizados numa função específica (HARDIMON, 1994, p. 334), convencionalmente determinada. A consequência de tal leitura leva o juiz, que despreza a aplicação concreta da regra e segue suas próprias convicções ou raciocínio moral, deixar de exercer seu papel como juiz, ou seja, ao decidir o caso fora dos cânones legais, o agente abandonou o exercício das funções inerentes ao seu papel social. De modo semelhante à baby-sitter que, momentaneamente, deixa de manter vigilância sobre as crianças para receber a correspondência do carteiro, o juiz deixa de manter vigilância sobre a regra que deveria estar aplicando. Logo, a impressão que tal juiz passa é de ter descumprido seu papel, e que tal descumprimento não pode ser permitido. Essa atitude do juiz geralmente é tomada como uma conduta de má-fé perante o ordenamento jurídico e à comunidade que vive relativamente tranquila com a regra que o juiz deixara de aplicar.

\footnotetext{
10 Tradição livre de "It has been suggested that laws are generalizations that predict the decisions of judges, that laws are norms addressed to judges, that laws are norms that judges are entitled to enforce, and that laws are norms that those subject to judicial decisions are required to obey."

11 Leslie Green (2014, p. 04) qualifica-a como uma visão simplista do papel judicial. Acredito que o filósofo esteja certo com essa caracterização, o que provocaria repensar a forma com que o papel judicial está configurada. Seria possível, por exemplo, considerar que o papel judicial não resta esgotado apenas por um conjunto de normas, valores e expectativas determinados somente pelo sistema jurídico que participa, mas por considerações morais que extrapolam os limites do direito institucionalizado. Porém, uma análise desse tipo ultrapassa os objetivos aqui almejados. Para defender a hipótese de que os juízes possam estar agindo sob a influência dos fatores psicológicos que serão trabalhados basta-se ater à impressão de que a função convencional do juiz é decidir conforme as regras claramente aplicáveis ao caso concreto.
} 
As consequências ${ }^{12}$ comumente atribuídas ao juiz "mal comportado" podem ser sanções administrativas pela má conduta perante o direito, afastamento temporário do cargo, ou até mesmo remoção em casos consecutivos de desobediência.

Desse modo, o pressuposto de que juízes devem aplicar padrões jurídicos para exercer seu papel está envolto por uma obrigação especial de fidelidade ao ordenamento jurídico. Especial, pois a obrigação de obediência dos juízes para com o direito é mais forte do que a de cidadãos comuns, cuja obrigação implica apenas respeito aos ditames legais. Juízes teriam então uma obrigação de aderir ${ }^{13}$ ao direito, ou seja, uma disposição proativa de zelar pela correta aplicação de padrões jurídicos (BALLARD, 2009, p. 39). Outro modo de expressar a obrigação de fidelidade é dizer que juízes têm uma razão moral significativa para julgar casos conforme o que o direito existente requer (REEVES, 2010, p. 163).

Porém, seria essa obrigação de aderir ao direito um tipo de dever peremptório aos juízes?

Os casos de regras espúrias tratados atuam contra o dever categórico de aderência ao direito. O filósefo Robert Cover (1984), é contrário a essa posição, cita o caso do conflito de consciência enfrentado por muitos juízes dos Estados Unidos durante o período escravocrata. Vários eram contra a escravidão, alguns poucos se rebelavam contra o regime, mas parcela significativa cedia à pressão e aderia à obrigação de fidelidade por temerem a remoção do cargo. Cover (1984, p. 201) teceu o seguinte comentário sobre a moralidade profissional dos juízes determinada pelo vínculo de fidelidade ao direito institucional:

a consciência judicial é uma trapaceira astuta... Antes dela reconhecer que um caso apresenta um dilema moral, se esconderá nos cantos e recantos da ética profissional, correrá para a caverna dos limites da função, e procurará abrigo na separação dos poderes $^{14}$.

\footnotetext{
12 Para uma análise mais detalhada à respeito das possíveis sanções ao juiz descumpridor das expectativas do papel de julgador, sugiro a leitura do Capítulo 4, "The Legal Duties of Judges" na obra de Brand-Ballard (2010, p. 56-73).

13 Termo de arte empregado por Ballard (2009) para diferenciar a obrigação geral ao direito de cidadãos da obrigação de fidelidade judicial.

14 Tradução livre de: "[t]he judicial conscience is an artful dodger, it will hide in the nooks and crannies of the professional ethics, run to the cave of role limits, [and] seek the shelter of separation of powers."
} 
A obrigação de fidelidade judicial invoca a necessidade de assegurar a observância das leis originadas, ou pelo consentimento voluntário, ou por ser alvo de um acordo mútuo e vantajoso entre os cidadãos. Para ilustrar essa necessidade há uma gama de teorias que explicam de diversos modos a obrigação política perante o Estado e às normas do direito. Como é o caso dos argumentos defendidos em teorias do consentimento, da associação política, do fair play, da gratidão ou samaritanismo, ou do dever político natural (DAGGER; LEFKOVITZ, 2014) (WELLMAN; SIMMONS, 2005) (KLOSKO, 2003). Porém, não faz parte das minhas intenções abordar qualquer das teorias de obrigação política, desejo apenas indicar que os exemplos de normas jurídicas espúrias são suficientes para que argumentos sobre a obediência política sejam vistos com maior ceticismo, como o apontado por Huemer ${ }^{15}$. (2012):

O Estado moderno reivindica um tipo de autoridade que obriga todos os outros agentes a obedecer os comandos do Estado, e autoriza o Estado a distribuir violência e ameaças de violência para reforçar seus comandos, independentemente se os comandos são por si mesmos justos, razoáveis ou benéficos ${ }^{16}$.

O ceticismo do filósofo quanto aos deveres de obediência o fez investigar quais possíveis causas de comportamento que levam pessoas a ter uma pró-atitude de agir conforme as leis de direito impostas pelo Estado. Debruçou-se sobre evidências encontradas em estudos de psicologia social sobre as atitudes e o comportamento de agentes sujeitos à autoridade, que são o objeto do próximo tópico.

\footnotetext{
15 Autores como Michael Huemer e John Simmons (WELLMAN; SIMMONS, 2005) são defensores do chamado anarquismo filosófico, teoria política que desconfia da capacidade que o Estado tem em impor deveres ou obrigações de obediência aos cidadãos. O anarquismo filosófico não deve ser confundido com a doutrina anarquista ordinária, que demonstra ceticismo e aversão à própria legitimidade do Estado. Adeptos do anarquismo filosófico geralmente são favoráveis à existência do Estado e reconhecem muitos de seus benefícios para a manutenção de uma sociedade, embora discordem do modo com que Estados tipicamente clamam sua autoridade.

16 Tradução livre de: "the modern state claims a kind of authority that obliges all other agentes to obey state's commands and entiles the state to deploy violence and threats of violence to enforce these commands, independente of whether the commands are in themsilves just, reasonable, or beneficial."
} 


\section{FATORES COMPORTAMENTAIS DE OBEDIÊNCIA}

Huemer (2012) menciona os estudos realizados por Stanley Milgram e Philip Zimbardo $^{17}$, bem como o de Solomn Asch para demonstrar como pessoas estão propensas a deferir à julgamentos de autoridade ou impor julgamentos de autoridade mesmo que suas consequências sejam reprováveis ou equivocadas. Adoto a seguir a mesma motivação de Huemer, mas opto por analisar apenas o experimento de Asch, e por acrescentar à discussão o caso da ignorância pluralista, já que acredito que tais vieses psicológicos de obediência expressam melhor a pressão que juízes têm de adesão ao direito, pela necessidade de aplicar os padrões institucionais e seguir a aceitação dos mesmos como padrões de conduta críticoreflexivos.

Como se viu, a conduta de um juiz que considera a presença de regras jurídicas ruins e despreza sua aplicação não é vista com bons olhos. Entretanto, as decisões contrárias às regras dos casos apresentados na introdução não seriam fruto de arbitrariedade ou mera irreflexão. Juízes poderiam decidir contra regras espúrias invocando razões persuasivas contra a sua persistência. Acredito que os juízes que chegaram ao veredito de afastar uma regra ruim para o caso dado raciocinaram cuidadosamente e atingiram uma decisão sensata, cujo resultado é comparativamente melhor do que aplicar a regra ${ }^{18}$. Mas se o juiz foi sensato e uma pequeníssima parcela da sociedade assim admite, deve haver uma causa comportamental que explique porque motivos há uma rejeição maior contra essa atitude judicial. Argumento que os experimentos apresentados demonstrarão: que juízes se sentem pressionados pelo

\footnotetext{
${ }^{17}$ Esses dois pesquisadores desenvolverem experimentos focados na obediência à autoridade e como a ocupação de uma posição de autoridade altera o comportamento social dos sujeitos. Milgram (2009), em seu famoso experimento do choque elétrico, submeteu agentes a infligir choques elétricos a cada resposta errada de um cobaia. Os choques nunca eram verdadeiros, só encenados pela vítima, mas o experimento demonstrou que ao assumir uma posição de autoridade, pessoas perdiam o foco moral sobre as consequências de suas ações e decidiam apenas por estarem determinadas a agir conforme a posição assumida. Já Zimbardo (2008), conduziu um experimento em que os sujeitos deveriam simular os papéis típicos de um presídio, cada agente assumia um papel, dos detentos aos agentes penitenciários. Os resultados do experimento demonstraram que os sujeitos ocupantes de posições hierárquicas superiores passaram a atitudes autoritárias e perversas contra os detentos. Também concluiu que os efeitos da obediência às funções de autoridade podem ser prejudiciais.

${ }^{18}$ É sensato argumentar que a decisão do juiz tem impacto negativo à outra parte da disputa judicial. Por exemplo, no caso da missão de caridade de Madre Teresa, a municipalidade de Nova Iorque sairia derrotada por uma decisão que não aplicou a regra da forma esperada, e no caso do tráfico de drogas, afastado pelo princípio da significância, afetaria a pretensão condenatória do Ministério Público. Desse modo, como afirmar que a decisão é melhor? O ponto sustentado é de que mesmo que uma parte do processo ou terceiros sofram algum prejuízo, a decisão atípica do juiz produziu um resultado que é pro tanto mais adequada de um ponto de vista moral, ou seja, é, nos limites do razoável, melhor do que a decisão que aplica a regra espúria.
} 
comportamento formalista de sempre aplicar padrões jurídicos, e que tal comportamento ocorre na mesma proporção da oposição majoritária à atitudes contra legem.

A seguir, seguem os casos comportamentais.

\subsection{O experimento de Solomon Asch}

Em 1955, Solomon Asch (1955, p. 19-26) conduziu um simples experimento para avaliar a relação entre o conformismo e a submissão a julgamentos entre os participantes. $\mathrm{O}$ exame consistia num processo de comparação visual do tamanho de linhas traçadas em dois painéis, o primeiro sempre composto por uma única linha adotada como parâmetro de comparação e os demais painéis compostos por conjuntos de três retas com comprimentos variados. Os sujeitos testados eram colocados em grupos e deveriam dizer quais das linhas em sequência expostas no segundo painel tinham o mesmo comprimento da linha parâmetro do primeiro painel. Logo abaixo, segue uma representação do experimento:
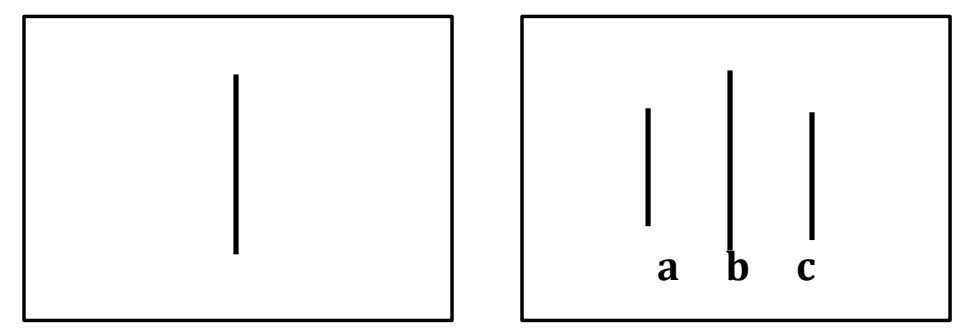

Cada sujeito deveria anunciar suas respostas na ordem com que estavam sentados na sala. O teste envolveu duas amostragens distintas de sujeitos: a primeira composta por grupos em que todos os sujeitos receberam a mesma instrução de escolher a linha cujo comprimento fosse idêntico ao parâmetro; e a segunda composta por grupos de pessoas em que todos, menos um único sujeito alvo do teste, foram instruídos a dar respostas visualmente equívocas durante as rodadas comparatórias (BOCCHIARO; ZAMPERINI, 2012, p. 276-278)

O objetivo do psicólogo, ao cruzar os dados de cada amostragem de testados, era estudar o impacto do conformismo sobre um agente quanto este é exposto em situações onde sua opinião é a minoritária. O sujeito-alvo da segunda amostragem do experimento é colocado justamente nessa posição, pois o experimento foi formulado de modo que o sujeito testado, sem saber que os demais foram instruídos a errar propositalmente, ocupava sempre o último assento e era o último a deliberar sobre o comprimento das linhas. Desse modo, o sujeito-alvo era colocado em uma inesperada posição minoritária, oposta a uma unanimidade majoritária e arbitrária. As conclusões obtidas após várias séries de testes demonstraram que, entre mais de uma centena 
de sujeitos testados pela segunda amostragem, parcela significativa se rendeu às escolhas equívocas da maioria. O cruzamento dos resultados também demonstrou que enquanto em circunstâncias normais o índice de erros de julgamento eram inferiores a 1\%, os sujeitos da amostragem enviesada passaram a ter um índice de erro em 36,8\% das escolhas.

Asch também conduziu outra série de experimentos confrontando o sujeito-alvo contra apenas um rival que contradizia a escolha correta, depois contra dois e mais rivais. Os resultados demonstraram que o índice de escolhas equívocas subiu de 13,6\% no primeiro cenário, para 31,8\% no cenário em que a maioria equivocada era composta por três sujeitos. Após outros aumentos, o psicólogo não encontrou elevações mais expressivas de escolhas erradas, mesmo que os índices de erro ainda subissem em escala menor.

Por fim, Asch também testou um arranjo no qual o sujeito-alvo possuía um "parceiro", propositalmente instruído a concordar com o sujeito na maioria dos casos. Os dados demonstraram que o fim da unanimidade reduziu muito da influência da maioria sobre as escolhas dos testados (em torno de um terço em geral; e em análises pontuais a redução foi maior). Na presença do parceiro os testados passaram a demonstrar maior confiança no seu julgamento pessoal.

O que a série de experimentos de Asch revela é a força que os julgamentos de sujeitos em grupos majoritários têm sobre as escolhas individuais de cada pessoa. Quanto maior é a influência da decisão majoritária, maior é a pressão por conformidade exercida sobre a decisão individual.

Outro dado curioso diz respeito ao grupo minoritário de sujeitos (cerca de um quarto entre todos os testados) que se mantiveram convictos às suas próprias percepções. Segundo Bocchiaro e Zamperini (2012, p. 277):

Um comentário relatado ao final do experimento por um dos sujeitos avaliados é
exemplar: 'não imaginei estar errado, mas a razão me disse que estava errado,
porque era impossível tantas pessoas estarem erradas e somente eu estar certo'.
Mesmo os poucos que nunca conformaram com as respostas da maioria confessaram
que experimentaram uma profunda sensação de inquietação e dolorosa incerteza ${ }^{19}$.

Os autores também descrevem relatos fornecidos entre os testados que se conformaram com as decisões equívocas da maioria. Muitos afirmam que começaram a desconfiar de sua capacidade visual ou decidiram conforme o grupo por temerem alguma atitude de rejeição do grupo contra a escolha vencida ou mesmo por não desejarem parecer estúpidos perante as escolhas da maioria (BOCCHIARO; ZAMPERINI, 2012, p. 277). 
19

One comment reported at the end of the experiment, by one of the critical subjects is exemplary: "I didn't think I was mistaken, but reason told me I was wrong because it was impossible that so many people could be wrong and that only I was right". Even the few that never conform to the responses of the majority confessed that they had experienced a profound sense of unease and a painful uncertainty.

\subsection{O rei está nu! O que é a ignorância pluralista}

A ignorância pluralista é outro viés comportamental estudado pela psicologia social, que, a priori, soa difícil de ser compreendido, mas é bem fácil de ser ilustrado.

Grosso modo, o fenômeno explica a persistência de julgamentos equivocados através do modo com que cada sujeito imagina qual deve ser a opinião expressa pela maioria dos sujeitos com que convive. Se certo grupo convive sob um estado de ignorância pluralista, a maioria dos sujeitos mantém a condição psicológica de crer que seus pensamentos, sentimentos ou atitudes particulares sejam diferentes daqueles mantidos por outros, embora o comportamento público do agente seja idêntico às atitudes vistas nos demais (BICCHIERI, 2006, p. 186). A ignorância pluralista é então marcada por uma assimetria entre crenças e atitudes, na medida em que o agente pensa de um modo, mas, ao invés de agir do modo que pensa, age conforme acreditam que os outros pensam ${ }^{20}$.

Um conceito que capta em detalhes o fenômeno é o seguinte:

\footnotetext{
"ignorância pluralista” refere-se à situação em que membros individuais de um grupo:

i) Todos acreditam intimamente em alguma proposição $P$;

ii) Todos acreditam que todo o mundo acredita em $\neg P$;

iii) Todos agem contrariamente à sua crença intima de que $P$ (i. e., agem como se acreditassem em $\neg P$ ), $e$ onde

iv) Todos tomam as ações dos outros como evidência forte para suas crenças intimas sobre P. (BJERRING et. al, 2014, p. 2460). ${ }^{21}$
}

Um exemplo de ignorância pluralista é encontrado na literatura infantil. Hans Christian Andersen (2007) narra, em “A Roupa Nova do Rei”, a fábula de um rei muito vaidoso, que adorava se vestir bem. Certo dia, o monarca obcecado pela vaidade, foi ludibriado por dois vigaristas que se passaram por alfaiates. Os costureiros prometeram presentar o rei com uma obra máxima de alfaiataria: uma roupa de rara beleza, tão rara somente poderia ser vista por pessoas inteligentes e laboriosas. Toda a corte do rei, preocupada em agradar a majestade, admitia a beleza sem igual da vestimenta e a habilidade assombrosa dos alfaiates, afinal de contas, nenhuma pessoa gostaria de demonstrar perante o rei e aos demais que não era inteligente, muito menos pouco dedicada ao trabalho. Na fantasia

\footnotetext{
20 O’Gorman (1986, p. 333) afirma que a ignorância pluralista "não é uma ignorância na acepção ordinária de não saber. Pelo contrário, é o conhecimento de outros que é enganosamente considerado ser correto" (trad. livre).

21 Tradição livre de "“Pluralistic ignorance" refers to a situation where the individual members of a group (i) all
} 
privately believe some proposition P; (ii) all believe that everyone else believes $\neg \mathrm{P}$; (iii) all act contrary to their private belief that $\mathrm{P}$ (i.e. act as if they believe $\neg \mathrm{P}$ ); and where (iv) all take the actions of the others as strong evidence for their private beliefs about P."

de Andersen, o próprio rei também não conseguia enxergar a roupa imaginária, mas também disfarçava o fato, para não entregar aos súditos que era burro, afinal de contas, a expectativa de todos era que os reis fossem sempre sagazes. Quando a roupa nova do rei ficou pronta, uma festa pública foi organizada para mostrá-la, o monarca "vestiu" os trajes e desfilou nu entre os súditos. Todo povo mantinha as aparências, menos um garoto despretensioso que apontou: “mas o rei está pelado!'. Muitos ainda pensaram, "mas que pobre ingênuo, é burro...", até que pouco a pouco o povo realmente se deu conta de que o rei realmente desfilava nu, e que os vigaristas enganaram não só o rei, mas a todos.

A estória de Andersen indica um caso bem exagerado de ignorância pluralista, no qual parcela quase unânime dos súditos, apesar de acreditar que o rei realmente estivesse nu, externalizavam concordância justamente pelo contrário, que o rei vestia uma roupa magnífica. Noutras palavras, a opinião que um sujeito tinha era tomada por ele como equívoca, pois projetava erroneamente em pensamento que o resto da comunidade não compartilhava a mesma convicção. Logo, a comunidade, de modo geral, agia em erro.

Outro exemplo, mais concreto e comum, é o caso da sala dos alunos inteligentes: não é raro que professores, após explicar um ponto bem complexo da disciplina, perguntar aos alunos se existe alguma dúvida, mas ninguém se dispõe a levantar a mão solicitando esclarecimentos. Nenhum aluno levanta a mão por temer ser publicamente exibido como o único que não entendeu a aula, embora muitos tenham ficado com dúvidas (BJERRING et. al., 2014, p. 2450).

Interessante notar que a ignorância pluralista não é um comportamento psicológico puramente irrefletido ou mesmo irracional. $\mathrm{O}$ agente que age em estado de ignorância pluralista está ciente de que se agisse conforme realmente pensa talvez fosse uma alternativa mais razoável, só não o faz por temer a pressão da opinião pública. Segundo Bjerring et. al (2014, p. 2462), ações ou crenças são capazes de produzir situações pragmáticas que são valorizadas por pessoas, pois promovem interesses práticos estimados pela maioria da comunidade. Tomando os exemplos dados novamente, tanto os súditos do rei, quanto os alunos, não agem de acordo com seus estados mentais genuínos, por acreditarem que a situação pragmática mais valiosa é não causar algum distúrbio ou comoção que julgam (mesmo erroneamente) inadequados. 
Mas, e quanto aos juízes? O julgador que considera uma regra jurídica espúria tem certa semelhança ao garoto do conto que afirma que o rei estava nu, ou seja, ele representa o caso de um agente que não age sob a ignorância pluralista, ou leva menos em conta a reprovação da opinião pública.

\subsection{Os vieses comportamentais explicam bem a persistência de regras espúrias?}

Não é de todo implausível ou improvável considerar que parcela significativa da sociedade e dos juízes intimamente considere que certa regra jurídica é espúria e que não deveria ser aplicada a certos casos particulares. Mas, pelos exemplos expostos, qualquer pessoa está sujeita a propensões comportamentais que obscurecem seus julgamentos mais íntimos e razoáveis. Os experimentos de Asch e a ignorância pluralista são vieses psicológicos capazes de agir negativamente sobre capacidade de deliberação dos sujeitos. Pessoas influenciadas por tais vieses sofrem pressões que dificultam, senão impedem, que convicções individuais minoritárias, embora corretas, prevaleçam.

Se quaisquer pessoas estão sujeitas aos efeitos da conformidade e da submissão às decisões impostas pela maioria é grande a probabilidade de juízes também agirem sob os mesmos efeitos. Como expus nas seções 1 e 2 , juízes estão envoltos por uma função regulada institucionalmente pelo ordenamento jurídico, e sofrem uma cobrança institucional não apenas pelas decisões de seus pares expressas num precedente ou entendimento jurisprudencial, como também pelas pessoas que depositam confiança no estado de direito e pelas regras jurídicas que reivindicam autoridade para solucionar um caso concreto.

Acredito que a influência desses vieses contribuem para a reprodução do discurso de que regras jurídicas devem ser preservadas contra decisões particulares de juízes, ou reforçam a convicção de juízes estarem adstritos apenas ao formalismo ou a um raciocínio baseado em regras. A presença dos vieses também aumenta o ceticismo relacionado ao comportamento ativista do juiz, criticado por violar preceitos como da separação de poderes, pois o juiz não teria legitimidade para afastar as regras, já que seria função do legislador, representante do povo, alterar a regra, caso fosse prejudicial.

Porém, essas convicções não resolvem o problema. Afinal de contas, os legisladores, e própria população responsável por elegê-los, também estão sob os efeitos da submissão e conformidade a escolhas majoritárias, materializadas nas atitudes dos oficiais do direito e pelos padrões jurídicos espúrios expressos no ordenamento. Desse modo, a responsabilidade 
de desconsiderar um padrão jurídico ruim pode até mudar de mãos, mas dificilmente alguma alteração será tomada.

Ao analisar a ação de vieses psicológicos dos sujeitos sobre normas não-formais, Brennan et. al (2013, p. 183) esclarecem que, curiosamente, pessoas não conseguem perceber que a observância de uma norma não implica necessariamente em adesão à mesma. Agindo desse modo, há falta de opinião crítica contra atitudes sociais e normas indesejáveis. Outros fatores que associam à persistência de normas espúrias causados pelos dois fenômenos explorados é a onerosidade para alterá-las. A onerosidade aos juízes está na dificuldade de alterar a crença generalizada em favor do formalismo

O fator da onerosidade é particularmente relevante quando se trata de regras de um ordenamento jurídico. Ordenamentos de regras jurídicas estão vinculados à comunidade política que majoritariamente escolheu os representantes políticos do Estado que editaram ou recepcionaram regras jurídicas. Nesse sentido, regras jurídicas transparecem uma noção de instituição à qual pessoas depositam (ao menos deveriam depositar) confiança para administrar suas vidas. A existência de uma ordem jurídica de regras comumente aceitas e obedecidas produz uma situação de normalidade ou convencionalidade. A sociedade passa a internalizar padrões de conduta como deveres de obediência. Segundo March e Olsen (1984, p. 743):

\begin{abstract}
Instituições simplificam a vida política ao assegurar que algumas coisas sejam tomadas como dadas. Instituições fornecem códigos de comportamento apropriado, laços afetivos, e uma crença em uma ordem legítima. Regras e práticas especificam o que é normal, o que deve ser esperado, o que pode ser invocado, e o que faz sentido na comunidade, i.e., o que se espera em várias situações de um cidadão, representante eleito, administrador, ou juiz ordinários - razoáveis e responsáveis (mas falíveis). ${ }^{22}$
\end{abstract}

Portanto, é comum a tendência de depositar nas regras a tarefa de regular práticas e condutas. Se a confiança na eficiência das instituições jurídicas for firme, a crença na importância de respeitar regras devidamente editadas tende a aumentar. Mesmo que nem todas as regras sejam adequadas a certas situações concretas específicas, na maior parte dos casos eles cumprem adequadamente bons propósitos.

\footnotetext{
22 Tradução livre de "Institutions simplify political life by ensuring that some things are taken as given. Institutions provide codes of appropriate behavior, affective ties, and a belief in a legitimate order. Rules and practices specify what is normal, what must be expected, what can be relied upon, and what makes sense in the community, i.e. what a normal, reasonable and responsible (yet fallible) citizen, elected representative, administrator, or judge, can be expected to do in various situations."
} 
Essas reflexões acerca da importância de instituições e da onerosidade necessária para se alterar atitudes associadas à obediência das regras são fatores que podem assomar às propensões comportamentais estudadas. Caso oficiais do direito vejam um sistema de regras como padrões de adjudicação decisivos e infestáveis, não terão a predisposição de considerar uma regra espúria quando casos particulares inesperados surgem. A atitude mais simples, ou mais cômoda, parece realmente guardar obediência à regra do que arriscar desconsiderá-la e enfrentar a crítica e a oposição de um grupo majoritário. Ao menos a priori, a comunidade em geral aparenta estar satisfeita, todos manifestam aparente observância e adesão às regras.

Porém, sobretudo se a ignorância pluralista estiver em ação, muitas pessoas devem equivocadamente estar agindo em endosso a regras espúrias pela mera adesão da maioria, ou apenas para preservar uma situação de normalidade. No entanto, se não temos motivos plausíveis para aderir ao julgamento da maioria, devemos nos esforçar para demonstrar o valor de nossas opiniões contrárias. O filósofo David Lyons (1984, p. 17) deixa uma importante lição:

Minha opinião moral não deve ser descartada somente porque ela é não convencional. A moralidade convencional pode ser sensatamente desafiada. Para aceitar isso, não precisamos assumir que meu julgamento não conformista é correto. Posso reconhecer que posso estar errado, pois não preciso ser dogmático. Mas muito menos devo considerar confiáveis os padrões dominantes. ${ }^{23}$

Enquanto posturas obstinadas de conformidade a regras forem preservadas, muitos sujeitos se veem impedidos de promover ações valiosas (como no exemplo da Madre Tereza), ou são punidos pesadamente por práticas pouco reprováveis (caso do tráfico ínfimo de droga).

\footnotetext{
23 Tradução livre de: "My moral opinion is not to be discounted just because it is unconventional. Conventional morality can sensibly be challenged. To accept this, we do not need to assume that my nonconforming moral judgement is correct. I can recognize that might be mistaken, for I need not be dogmatic. But neither must I regard prevailing standards as sound".
} 


\section{CONCLUSÃO}

Apresentei hipóteses nas quais, regras jurídicas perfeitamente editadas, válidas, e legitimadas pelo ordenamento jurídico podem ser simplesmente ruins, espúrias, ou inadequadas caso aplicadas nalguns casos particulares. Também expus que juízes, que identificam um padrão legal inadequado e almejam desconsiderar sua aplicação, encontram forte oposição tanto dos seus pares, quanto do próprio ordenamento jurídico e de parte da opinião pública. A hipótese de um juiz desconsiderar padrões jurídicos claramente aplicáveis é vista com estranheza, já que o papel judicial é tipicamente associado somente à obediência e à aplicação das regras de um ordenamento.

Sustentei que dois vieses comportamentais relacionados à obediência por submissão e conformidade a decisões majoritárias são causas associáveis à persistência de padrões jurídicos espúrios na atividade judicial decisória. Os dois efeitos psicológicos impedem a alteração dos padrões crítico-reflexivos dos juízes, que se sentem pressionados a conformar com o direito regulado institucionalmente, mesmo que vereditos mais razoáveis pudessem ser alcançados de outro modo.

\section{REFERÊNCIAS BIBLIOGRAFICAS}

ANDERSEN, Hans Christian. A roupa nova do Rei. In: ANDERSEN, Hans Christian. Histórias Maravilhosas de Andersen. Trad. Heloísa Jahn.1 $1^{\mathrm{a}}$ ed. São Paulo: Companhia das Letrinhas, 2007. p. 15-21.

ASCH, Solomon E. Opinions and Social Pressure. In: Scientific American, v. 193, n. 5, 1955, p. 17-26. Disponível em: http://www.radford.edu/ jaspelme/_private/gradsoc_articles/obedience/Asch_1955.pdf. Acesso em: 20 abr. 2015.

BIDDLE, Bruce J. Role Theory, Expectations, Identities, and Behaviors. $1^{\mathrm{a}}$ ed. Nova Iorque: Academic Press, 1979. 416p.

BJERRING, Jens Christian;et. al. On the rationality of pluralistic ignorance. In: Synthese, v. 191, n. 11, jul. 2014, p. 2445-2470. Disponível em: http://link.springer.com/article/10.1007\%2Fs11229-014-0434-1. Acesso em: 02 jan. 2015.

BRAND-BALLARD, Jeffrey. Limits of Legality - The Ethics of Lawless Judging. $1^{\mathrm{a}}$ ed. Oxford: Oxford University Press, 2010. 354p.

BRASIL. Superior Tribunal de Justiça. Processo Penal. Habeas Corpus. Tráfico ilícito de

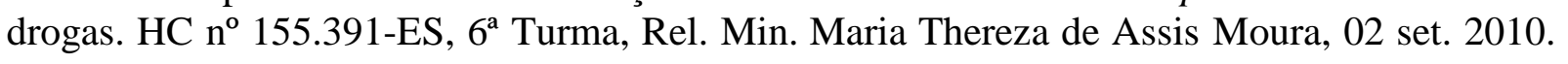


Disponível em: http://stj.jusbrasil.com.br/jurisprudencia/16677184/habeas-corpus-hc-155391es-2009-0234881-9/inteiro-teor-16996507. Acesso em: 02 jul. 2015.

BRASIL. Superior Tribunal de Justiça. Processo Penal. Habeas Corpus. Tráfico ilícito de drogas. 240.258-SP, 5 ${ }^{\text {a }}$ Turma, Rel. Min. Laurita Vaz, 13 ago. 2013. Disponível em: http://stj.jusbrasil.com.br/jurisprudencia/23942152/habeas-corpus-hc-240258-sp-20120081813-2-stj/inteiro-teor-23942153. Acesso em: 02 jul. 2015.

BRENNAN, Geoffrey; et al. Explaining Norms. $1^{\text {a }}$ ed. Oxford: Oxford University Press, 2013. 304p.

BICCHIERI, Cristina. The Grammar of Society - The Nature and Dynamics of Social Norms. $1^{a}$ ed. Cambridge: Cambridge University Press, 2006. 278p.

BOCCHIARO, Piero; ZAMPERINI, Adriano. Conformity, Obedience, Disobedience: The Power of the Situation. In: ROSSI, Giana (ed.). Psychology - Selected Papers. $1^{\mathrm{a}}$ ed. Rijeka: InTech, 2014. Cap. 14, p. 275-294. Disponível em: http://www.intechopen.com/books/psychology-selected-papers/conformity-obediencedisobedience-thepower-of-the-situation. Acesso em: 20 abr. 2015.

COVER, Robert M. Justice Accused: Antislavery and the Judicial Process. $1^{\text {a }}$ ed. Yale: Yale University Press, 1984. 322p.

DAGGER, Richard; LEFKOWITZ, David. Political Obligation. In: Stanford Encyclopedia of Philosophy, 2014. Disponível em: http://plato.stanford.edu/entries/political-obligation/. Acesso em: 27 jul. 2015.

GOLDSWORTHY, Jeffrey. The Limits of Judicial Fidelity to Law: The Coxford Lecture. In: Canadian Journal of Law and Jurisprudence, v.. 24, n.1, jul. 2011, p. 305-325. Diponível em: http://papers.ssrn.com/sol3/papers.cfm?abstract_id=2138710. Acesso em: 14 ago. 2014.

GREEN, Leslie. Law and the Role of a Judge. In: Oxford Legal Studies, v. 47, 2014, p. 1-30.

HARDIMON, Michael O. Role Obligations. In. Journal of Philosophy, vol. 91, 1994. pp. 333-63.

HART, Herbert L. A. O Conceito de Direito. $2^{\mathrm{a}}$ ed. Lisboa: Gulbekian-Calouste, 1994.

HUEMER, Michael. The Problem of Political Authority: An Examination of the Right to Coerce and the Duty to Obey. $1^{a}$ ed. Hampshire: Palgrave Macmillan, 2012. [edição ebook].

HURD, Heidi. O Combate Moral. Trad. Edison Bini. $1^{\text {a }}$ ed. São Paulo: Martins Fontes, 2003. $484 \mathrm{p}$.

KLOSKO, George. Political Obligations. $1^{\text {a }}$ ed. Oxford: Oxford University Press, 2005. 266p.

LYONS, David. Ethics and the Rule of Law. $1^{\mathrm{a}}$ ed. Cambridge: Cambridge University Press, 1984. 229p. 
MARCH, James G.; OLSEN, Johan P. The New Institutionalism: Organizational Factors in Political Life. In: The American Political Science Review, v. 78, n. 3, set. 1984, p. 734-749. Disponível em:http://chenry.webhost.utexas.edu/core/Course\%20Materials/March1984/0.pdf. Acesso em: 30 dez. 2014.

MILGRAM, Stanley. Obedience to Authority: An Experimental View. $1^{\text {a }}$ ed. Nova Iorque: Harper Perennial, 2009. 256p.

MOORE, Michael S. Four Reflections on Law and Morality. In: William \& Mary Law Review, v. 48, n. 5, 2007, p. 1523-1569. Disponível em: http://scholarship.law.wm.edu/cgi/viewcontent.cgi? article=1185\&context=wmlr. Acesso em: 21 abr. 2015.

MURPHY, Mark C. Philosophy of Law - The Fundamentals. $1^{\mathrm{a}}$ ed. Blackwell: Blackwell Publishing, 2007. 214p.

O'GORMAN, Hubert J. The discovery of pluralistic ignorance: An ironic lesson. In: Journal of the History of the Behavioral Sciences, v. 22, n. 4, p. 333-347. Disponível em: http://onlinelibrary.wiley.com/doi/10.1002/1520-6696(198610)22:4\%3C333::AIDJHBS2300220405\%3E3.0.CO;2-X/abstract. Acesso em: 05 jan. 2015.

SCHAUER, F. Is There a Psicology of Judging? In: KLEIN, David. E.; MITCHELL, Gregory. The Psychology of Judicial Decision Making. $1^{\mathrm{a}}$ ed. Oxford: Oxford University Press, 2010. Cap. 7, p. 103-120.

SHAPIRO, Scott J. Judicial Can't. In: Philosophical Issues, v. 11, n. 1, out. 2001. p. 530-557.

TARDELLI, Brenno; GARCIA, Nathalie. Insignificância: homem é condenado pelo STJ por tráfico de 0,02g de maconha. In: Justificando, 22 jun. 2015. Disponivel em: http://justificando.com/2015/06/22/insignificancia-homem-e-condenado-pelo-stj-por-traficode-002g-de-maconha/. Acesso em 02 jul. 2015.

What is the Internal Point of View? In: Yale Law Scholl Working Paper Series, out. 2006, p. 1-22. Disponível em: http://papers.ssrn.com/sol3/papers.cfm?abstract id=937337. Acesso em: 04 dez. 2014.

WELLMAN, Christopher Heath; SIMMONS, John A. Is There a Duty to Obey the Law? $1^{\mathrm{a}}$ ed. Cambridge: Cambridge University Press, 2005. 216p.

WISTRICH, A.J.; GUTHRIE, C.; RACHLINSKI, J.J. Can judges ignore inadmissible information?: The difficulty of deliberately disregarding. In: University of Pennsylvania Law Review, n.153, 2005, p.1251-1345. Disponível em: http://scholarship.law.cornell.edu/cgi/viewcontent.cgi?article $=1019 \&$ context=lsrp_papers. Acesso em: 07 jun. 2015.

Disponível Inside the judicial mind. In: Cornell Law Review, n. 86, 2001, p. 777-830. http://scholarship.law.cornell.edu/cgi/viewcontent.cgi?article=1734\&context=facpub. Acesso em: 07 jun. 2015. 
ZIMBARDO, Philip. The Lucifer Effect: Understanding How Good People Turn Evil. $1^{\mathrm{a}}$ ed. Nova Iorque: Random House Trade Paperbacks, 2008. 576p. 